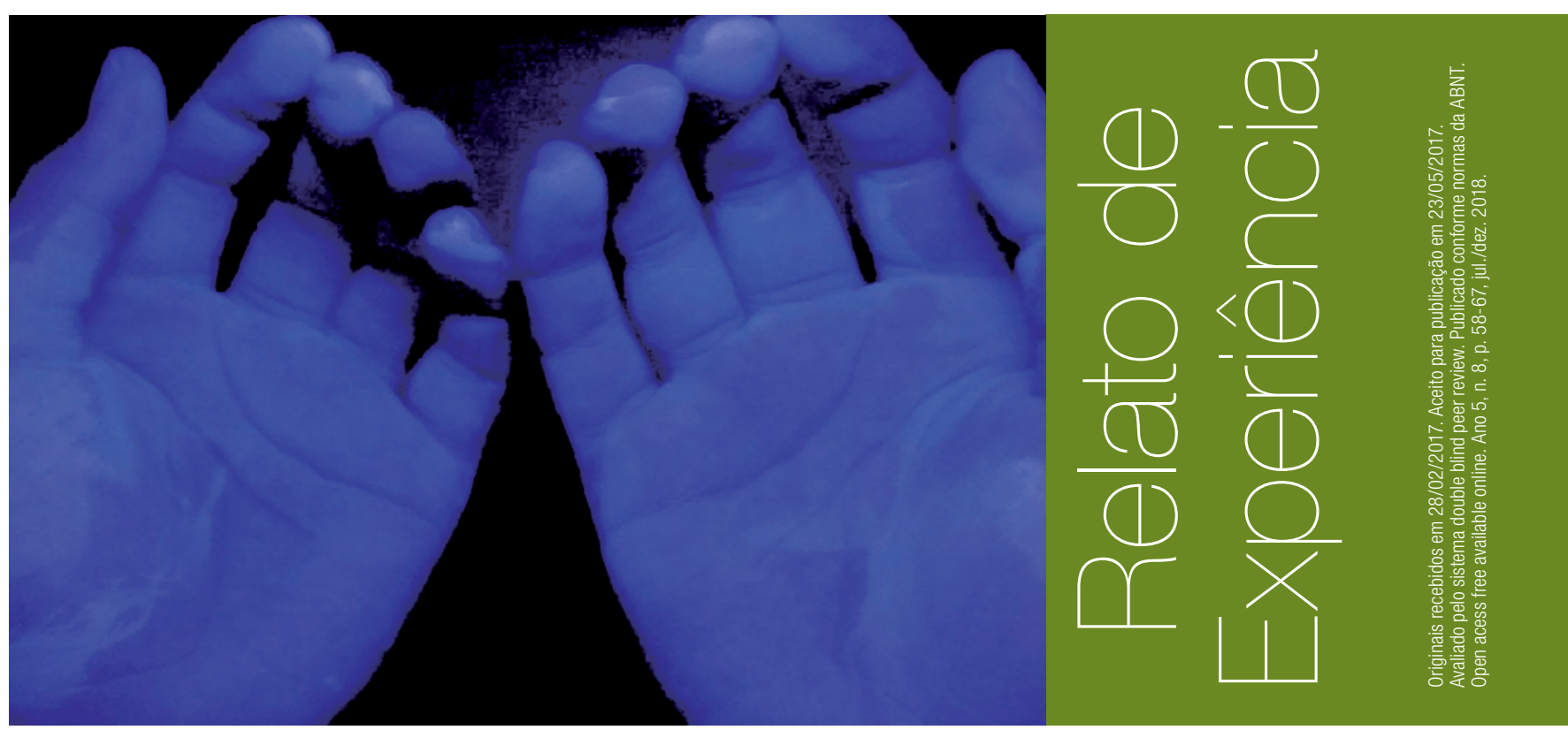

\title{
Promoção da higienização das mã̃os através de técnicas lúdico-educativas em um hospital público
}

\section{Bianca Clasen Gonçalves ${ }^{1}$ - bianca.clasen@outlook.com \\ Patrícia dos Santos Bopsin ${ }^{2}$ - patriciabopsin@cesuca.edu.br}

\section{RESUMO}

A higienização das mãos é considerada um ato simples, que causa um grande impacto na saúde, tornando-se prática indispensável em relação à assistência de enfermagem. Este trabalho tem por objetivo evidenciar o uso de técnicas lúdicas frente ao papel do enfermeiro como educador permanente, evidenciando a prevenção e promoção da saúde em um hospital público do Rio Grande do Sul, por meio de simulação realística. Destacou-se o déficit no processo de higienização as mãos, quanto à desinfecção, principalmente nas regiões do dorso das mãos e na porção superior dos polegares.

\section{PALAVRAS-CHAVE}

Educação em Enfermagem. Educação Continuada. Higiene das Mãos. Treinamento por Simulação.

\section{ABSTRACT}

The higienização of the hands is considered a simple action, that it causes a great impact in the health, becomingindispensablepracticeinrelationtothenursingattendance. Thisworkhasforobjectivetoevidence the use of techniques playful front to the nurse's paper as permanenteducator, evidencing the prevention and promotion of the health in a public hospital of Rio Grande do Sul, by means of realistic simulation. The deficit in the hand sanitization process was highlighted, as for disinfection, especially in the regions of the back of the hands and the upper portion of the thumbs.

\section{KEYWORDS}

Education in Nursing. Continuous education. Hygiene of the Hands. Training for Simulation.

\footnotetext{
1 Acadêmica de Enfermagem da Faculdade Inedi - Cesuca.

2 Enfermeira. Mestre em Ciências Médicas (UFRGS), Especialista em Gestão de Riscos e Segurança Hospitalar (UNISINOS). Docente do Curso de Enfermagem da Faculdade Inedi - Cesuca.
} 


\section{Relato de experiência}

Por caracterizar o cuidado integral, a equipe de enfermagem está exposta a diferentes riscos ocupacionais constantemente no dia a dia, sendo o risco biológico o mais frequente (BATHKE et al., 2013). De modo que as infecções hospitalares influenciam diretamente nos custos do atendimento decorrentes de terapêuticas complementares, além do aumento do tempo de permanência hospitalar e das taxas de morbimortalidade.

A Organização Mundial da Saúde reconhece a relevância da Higienização das Mãos (HM) e lançou em 2007 o programa Cuidado Limpo é Cuidado Seguro, estabelecendo estratégias de adesão à higienização das mãos. Este programa recomenda a HM frequente no contexto assistencial à saúde, enfatizando cinco momentos de oportunidades, sendo: 1) antes do contato direto com o paciente, 2) antes da realização de procedimento asséptico, 3) após exposição a fluidos corporais próximo ao paciente, 4) após o contato com o paciente e 5) após o contato com as áreas próximas ao paciente (WHO, 2009).

A higienização das mãos é considerada um ato simples, que causa um grande impacto na saúde, tornando-se prática indispensável no que tange à assistência em enfermagem. Esta técnica, se realizada corretamente, torna-se efetiva, atendendo o objetivo de eliminar os agentes patogênicos.

Este trabalho foi realizado a partir da disciplina Prática de Gestão em Enfermagem da Faculdade Inedi - Cesuca, em um hospital público e de pequeno porte da região metropolitana de Porto Alegre, no período de agosto a dezembro de 2017.

0 estudo se justifica por ser um tema estratégico dentro das organizações de saúde e por promover a conscientização da importância da higienização das mãos corretamente por todos os profissionais envolvidos no cuidado, desde colaboradores administrativos aos profissionais que prestam cuidado direto ao paciente, enaltecendo o papel do enfermeiro como educador permanente. E também reduzindo a transmissão de possíveis infecções e agravos à saúde.

Através do trabalho dos acadêmicos de enfermagem do $8^{\circ}$ semestre junto ao Controle de Infecção Hospitalar, viu-se a oportunidade de abordar ativamente 0 tema Higienização das Mãos com os colaboradores mediante a participação em cinco dias consecutivos na Semana de Enfermagem da instituição, tendo em vista a educação em saúde.

Foi utilizada como instrumento de educação uma caixa confeccionada de madeira, onde havia na parte anterior, duas entradas para as mãos, na porção superior um feixe para visualização interna e no interior, uma luz negra. A caixa foi pintada na cor preta fosca em seu interior para intensificar a luz negra. Utilizando álcool gel $70 \%$ com luminol para a demonstração das partes não limpas adequadamente.

Com 0 objetivo de aliar a ludicidade à prática assistencial, a dinâmica baseou-se em três personagens, caracterizados de "Sra. Bactéria", "Detetive" e um Enfermeiro. A bactéria "infectava" por onde passava, de modo que o detetive identificava a sujidade (Fig 1).

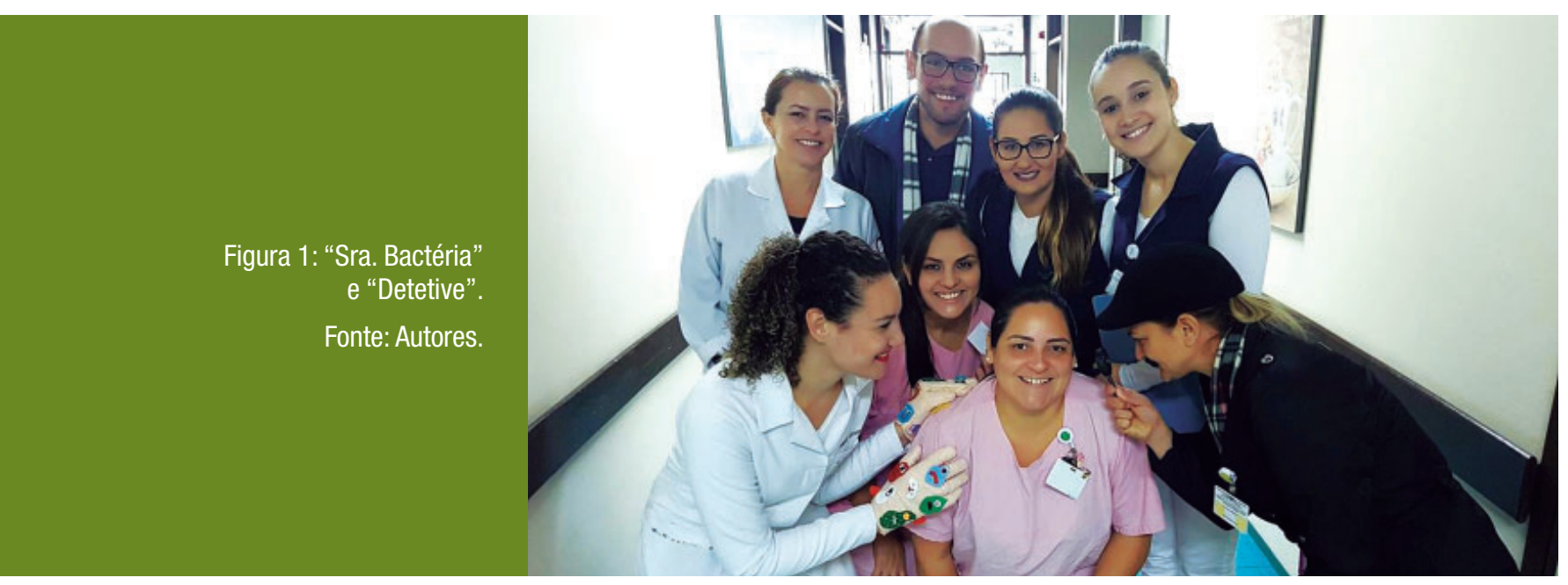


Logo após, a enfermeira disponibilizava o álcool gel com luminol ao profissional "infectado" para a higienização das mãos, conforme a prática diária e posteriormente o mesmo inseria suas mãos na "Caixa Misteriosa" para verificar a eficácia da higienização e de fricção (Fig. 2).

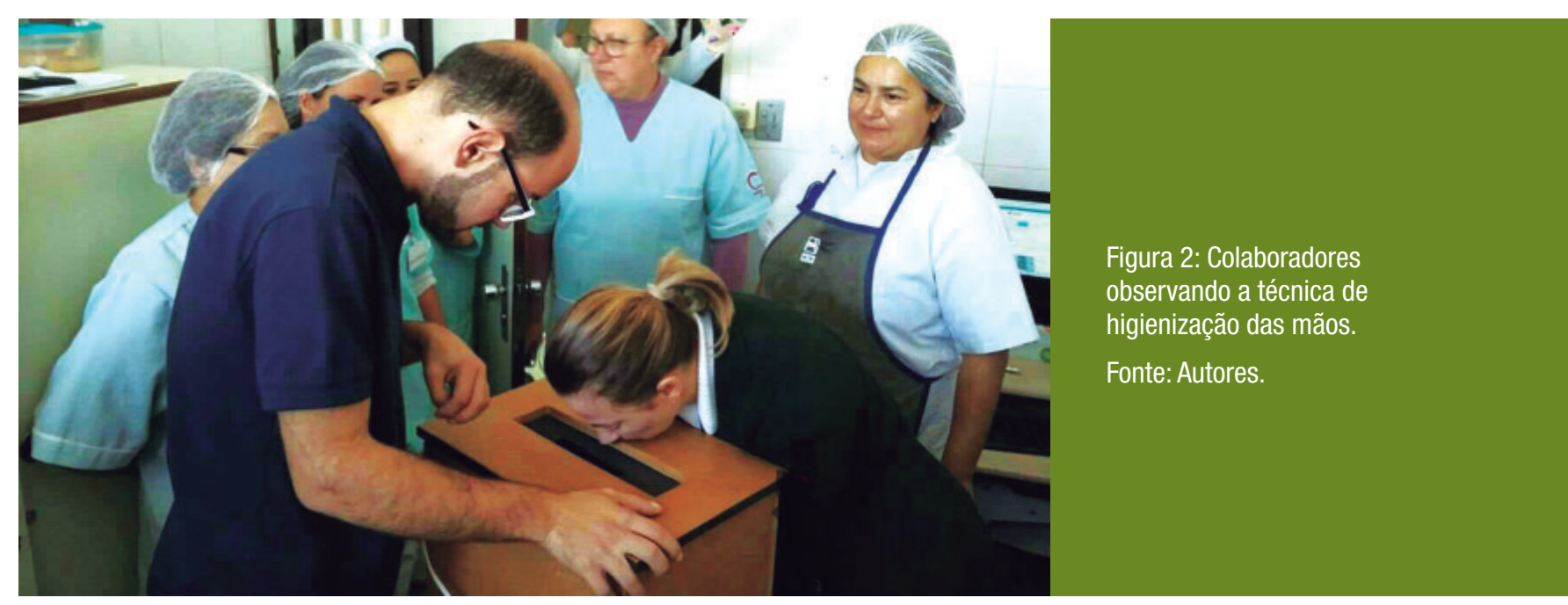

0 luminol junto ao álcool gel 70\% destacava as regiões onde a fricção foi efetiva, bem como nas regiões mais escurecidas, mostrava uma fricção não efetiva pela falta de álcool gel ou tempo de fricção (Fig. 03).

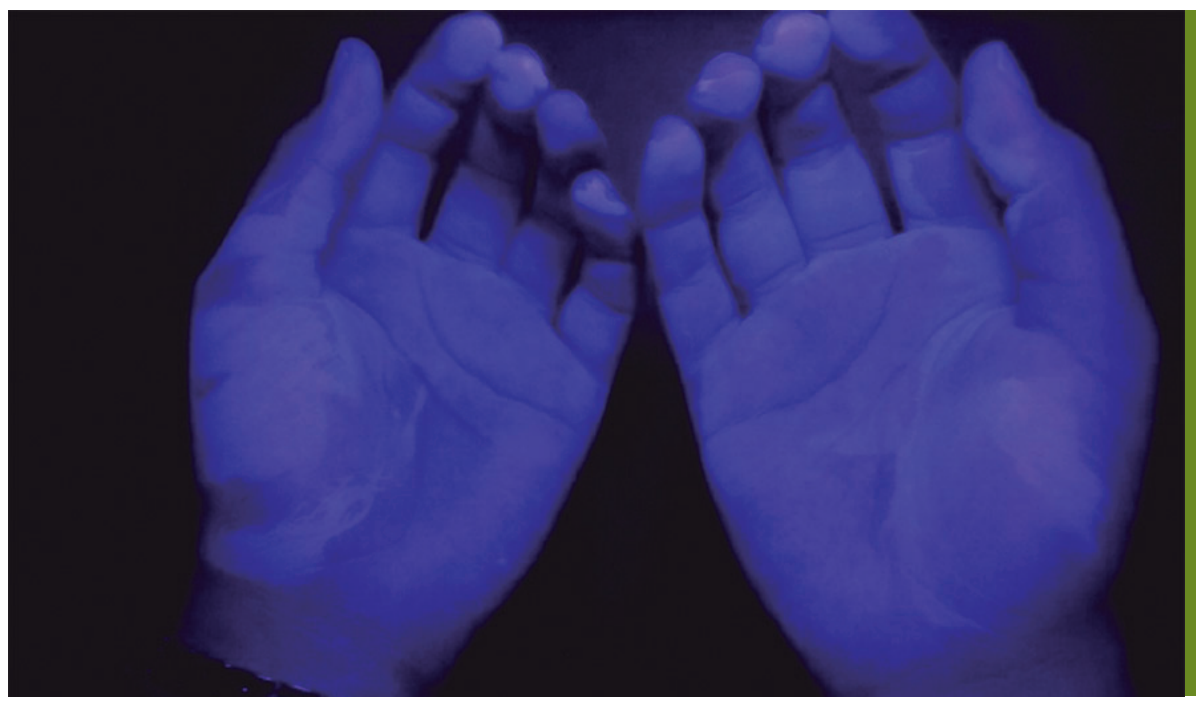

Figura 3: Efeito da luz negra com luminol.

Fonte: Autores.

Com a visualização de suas próprias mãos, houve questionamentos e esclarecimentos sobre quantidade de vezes do uso de álcool gel, tempo de fricção, quantidade de álcool gel a ser utilizado, fazendo com que suas práticas de HM fossem postas à prova.

Como resultado desta ação conjunta, destaca-se o déficit no processo de higienização as mãos, quanto à desinfecção, principalmente nas regiões do dorso das mãos e na porção superior dos polegares. Os enfermeiros foram os profissionais mais sucedidos no processo de HM.

A dinâmica teve 46 participações, alcançando todas as unidades da instituição, assim possuindo um caráter multidisciplinar, caracterizado por uma metodologia ativa de ensino. Este momento oportunizou uma reflexão sobre 0 ato de HM com diferentes categorias profissionais, além de esclarecer as dúvidas que foram surgindo.

A dinâmica realizada evidenciou, não somente a importância do ato de lavar as mãos, mas também a importância quanto aos recursos materiais disponíveis e estrutura física para que esta prática seja efetiva. Também, considera-se a motivação do profissional educador e a atualização periódica das técnicas de higienização das mãos. 
0 uso de simulação realística é uma estratégia inovadora para realização de treinamentos em instituições hospitalares, por reproduzir experiências do cotidiano sustentando um ambiente de interações entre os participantes, facilitando o processo de ensino-aprendizagem dos profissionais acerca da prevenção de infecções hospitalares.

\section{Referências}

BATHKE, Janaína et al. A. Infraestrutura e adesão à higienização das mãos: desafios à segurança do paciente. Rev Gaúcha Enferm, v. 34, n. 2, p.78-85. 2013.

World Health Organization. WHO Guidelines on Hand Hygiene in Health Care: First Global Patient Safety Challenge Clean Care is Safer Care. p.123. 2009. 